\title{
Self-Association and Stereoselectivity in a Chiral Liquid-Crystal Colesteric Polymer Formed under Achiral Conditions
}

\section{Mercedes Pérez-Méndez, ${ }^{\dagger}$ Roser Marsal Berenguel, ${ }^{\dagger}$ Leoncio Garrido, ${ }^{\dagger}$ and Manuel Martín-Pastor*,‡}

Instituto de Ciencia y Tecnología de Polímeros, CSIC, C/ J uan de la Cierva, 3. 28006 Madrid, Spain, and Laboratorio Integral de Estructura de Biomoléculas J ose R. Carracido, Unidad de Resonancia Magnética, RIAIDT, Universidad de Santiago de Compostela, 15782 Santiago de Compostela, Spain

Received J uly 13, 2003; Revised Manuscript Received August 20, 2003

\begin{abstract}
A cholesteric, chiral, liquid-crystal polyester PTOBEE $\left[\mathrm{C}_{26} \mathrm{H}_{20} \mathrm{O}_{8}\right]_{n}$, synthesized from the racemic mixture of their starting materials, showed an unexpected stereoselective separation of polymer units which incorporate a higher excess of one enantiomer at the expenses of the other when the polycondensation reaction products are decanted into a large excess of toluene. An NMR diffusion study of PTOBE E obtained for a sample with $67 \%$ enantiomeric excess (ee) showed the formation of a complex by self-association of several polymer units with an unexpected higher tendency of the complex to be formed when the sample is further diluted. Cross saturation transferred NMR experiments showed the high stability of this complex and provided evidence of slow exchange equilibrium with the single polymer unit. The results suggest that both effects, the enantiomeric excess obtained after decantation in toluene, which was higher in the second fraction of the precipitate, and the high tendency of the complex formation in diluted samples of this polymer could be related. Polymer units incorporating a certain excess of one of the enantiomers could result in a privileged spatial geometry of the substituents which favors its selfaggregation, resulting in its precipitation during the synthetic process at two different kinetic rates.
\end{abstract}

\section{Introduction}

Liquid crystalline polymers have attracted the interest of numerous theoretical and experimental investigations. ${ }^{1-4}$ Due to their anisotropic form or amphiphilic nature, the molecules are able to self-associate and/or aggregate in blocks to form species with supramolecular ordered structure which confer on them desirable material properties.

A synthetic method reported by Skorokhodov et al. ${ }^{5}$ based on polycondensation reaction was used for the synthesis of chiral liquid crystal polymer PTOBEE $\left[\mathrm{C}_{26} \mathrm{H}_{20} \mathrm{O}_{8}\right]_{n}$ (Figure 1). ${ }^{6-10}$ The method implies the decantation in toluene of the polycondensation reaction products. Although starting from racemic materials a chiral cholesteric liquid crystal polymer PTOBEE was obtained with $58 \%$ enantiomeric excess (ee). Later on, a new solid phase, identified as enriched PTOBEE with $67 \%$ ee precipitated. ${ }^{6-10}$

To gain further insight regarding the completely unexpected ee achieved, both PTOBEE polymer samples obtained with $58 \%$ and $67 \%$ ee were studied by current liquid NMR techniques which include NMR difffusion measurements, cross-saturation transferred (crossSTD), NOESY, T-ROESY, and variable temperature experiments among others.

NMR diffusion experiments have been applied to the study of liquid crystal polymers ${ }^{11}$ and other types of polymers either in their free form ${ }^{12,13}$ or when forming complexes. ${ }^{14,15}$ Self-association can be detected in these experiments by direct comparison of the diffusion coefficients ${ }^{16}$ by virtue of the relationship between the diffusion coefficient and the molecular size and shape, which are related to the molecular mass. ${ }^{14}$

* Corresponding author.

† Instituto de Ciencia y Tecnología de Polímeros, CSIC.

₹ Universidad de Santiago de Compostela.

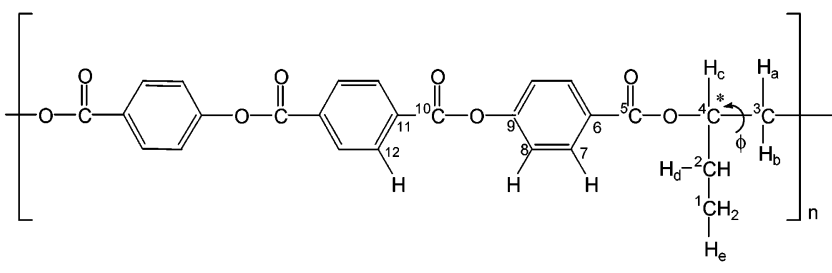

PTOBEE

Figure 1. Schematic view of the repeating unit of the polymer PTOBEE showing the numbering system used in the text. The chiral center at C-4 is indicated with an asterisk. The torsion angle $\phi$ studied in the text is also shown.

The cross-STD experiment has found important applications in the context of molecular recognition and ligand screening by NMR. ${ }^{17,18}$ This experiment has been used to detect molecules with a certain affinity to a receptor in a mixture of potential ligands 17,18 and to map the interaction surfaces for a ligand in a complex. ${ }^{19} \mathrm{~A}$ particular case also amenable to this type of experiment is to study self-association and/or aggregation equilibria. Providing any separated NMR signal can be found for any of the free species and/or in the complex aggregate, the cross-STD experiment could reveal the possible exchange among them in the form of signal enhancements, in a way very related with the NOE difference methods.

The solution structure of polymers and their complexes can be studied by NOESY, T-ROESY, and vicinal scalar couplings which can be interpreted in the frame of molecular mechanics molecular models. Some features of the possible exchange among conformations could be detected from the changes in line shapes and/ or chemical shifts which follow a change in the temperature. 
Table 1. ${ }^{1} \mathrm{H}$ and ${ }^{13} \mathrm{C}$ Chemical Shifts (ppm) for the Signals Observed for the Chiral Polymer PTOBEEc

\begin{tabular}{|c|c|c|c|c|c|c|c|c|c|c|c|}
\hline \multicolumn{8}{|c|}{ monomer polymer } & \multirow{2}{*}{\multicolumn{4}{|c|}{ complex }} \\
\hline \multicolumn{4}{|c|}{ enantiomer in excess } & \multicolumn{4}{|c|}{ enantiomer in defect } & & & & \\
\hline atom & ${ }^{1} \mathrm{H}(\mathrm{ppm})$ & atom & ${ }^{13} \mathrm{C}(\mathrm{ppm})$ & atom & ${ }^{1} \mathrm{H}(\mathrm{ppm})$ & atom & ${ }^{13} \mathrm{C}(\mathrm{ppm})$ & atom & ${ }^{1} \mathrm{H}(\mathrm{ppm})$ & atom & ${ }^{13} \mathrm{C}(\mathrm{ppm})$ \\
\hline $\mathrm{Ha}^{\prime}, \mathrm{Hb}^{\prime}$ & $4.63,4.54$ & $\mathrm{Ca}^{\prime}$ & 62.4 & $\mathrm{Ha}+\mathrm{Hb}$ & 3.78 & $\mathrm{Ca}$ & 41.81 & $\mathrm{Ha}^{\prime \prime}+\mathrm{Hb}^{\prime \prime}$ & 4.10 & Ca" & $a$ \\
\hline & 5.50 & $\mathrm{Cc}^{\prime}$ & 70.38 & $\mathrm{HC}$ & 5.27 & $\mathrm{Cc}$ & 71.71 & $\mathrm{HC}^{\prime \prime}$ & 5.415 & $\mathrm{CC}^{\prime \prime}$ & a \\
\hline $\mathrm{Hd}^{\prime}$ & 1.91 & $\mathrm{Cd}^{\prime}$ & 21.21 & $\mathrm{Hd}$ & 1.90 & $\mathrm{Cd}$ & 21.21 & $\mathrm{Hd}^{\prime \prime}$ & 1.85 & $\mathrm{Cd}^{\prime \prime}$ & 37.16 \\
\hline $\mathrm{He}^{\prime}$ & 1.10 & $\mathrm{Ce}^{\prime}$ & 6.60 & $\mathrm{He}$ & 1.04 & $\mathrm{Ce}$ & 6.60 & $H e^{\prime \prime}$ & 1.43 & $C e^{\prime \prime}$ & $b$ \\
\hline $\mathrm{H}^{\prime}$ & 8.18 & $C 7^{\prime}$ & 128.84 & $\mathrm{H} 7$ & 8.13 & C7 & 128.18 & $\mathrm{H} 7^{\prime \prime}$ & 6.56 & C7" & 124.19 \\
\hline $\mathrm{H} 8^{\prime}$ & 7.35 & C8' & 118.87 & $\mathrm{H} 8$ & 7.46 & C8 & 119.54 & H8" & 7.08 & C8" & 122.86 \\
\hline $\mathrm{H} 12^{\prime}$ & 8.36 & C12' & 127.51 & $\mathrm{H} 12$ & 8.29 & C12 & 128.18 & H12" & 7.07 & C12" & 124.86 \\
\hline
\end{tabular}

${ }^{a}$ Carbon signal was not observed due to its low intensity ${ }^{b}$ Overlap. ${ }^{c}$ Independent set of signals were obtained for each of the two types of enantiomeric repeating units in this polymer. Chemical shift data for a complex aggregate formed by self-association in a $67 \%$ ee sample of PTOBEE are also given.

\section{Experimental Section}

Synthesis of Cholesteric PTOBEE. Samples of the chiral polymer PTOBEE were synthesized according to the method previously reported. ${ }^{5-10}$ Two samples were obtained from the same reaction mixture and they are referred in the text according which their enantiomeric excess (ee). The first sample which precipitated after decantation in an excess of toluene, from the reaction products had a 58\% enantiomeric excess (ee). Later on, a more enriched solid preci pitated in the same toluene, from which PTOBEE was isolated with $67 \%$ ee.

NMR Experiments. NMR experiments were acquired on a $500 \mathrm{MHz}$ Bruker DRX-500 spectrometer using the XWIN NMR v 3.0 software distributed with the spectrometer. The spectra were processed and analyzed with MestRe-C software. ${ }^{20}$ The sample of PTOBEE used in the NMR experiments if not indicated otherwise had an ee $67 \%$, the concentration was $0.06 \mathrm{mg} / \mathrm{mL}$, the solvent was $\mathrm{CDCl}_{3}$, and the temperature was $300 \mathrm{~K}$.

${ }^{1} \mathrm{H}$ NMR dilution experiments were acquired for samples of PTOBEE $67 \%$ ee and $58 \%$ ee in $\mathrm{CDCl}_{3}$ at $300 \mathrm{~K}$ at the following concentrations: $7.5,3.75,1.87,0.94,0.47,0.23,0.12$, and $0.06 \mathrm{mg} / \mathrm{mL}$. The ee was determined by the integration of the signals of protons $\mathrm{Ha}, \mathrm{Hb}$, and $\mathrm{Hc}$ in an ${ }^{1} \mathrm{H}$ NMR spectrum obtained with $6 \mathrm{~s}$ delay between scans. These signals are conveniently well separated in the spectrum for each enantiomer. ${ }^{1 H}$ NMR experiments were acquired using $6 \mathrm{~s}$ interscan delay to ensure complete relaxation of the system as needed for a correct signal integration. Some signals were identified in the ${ }^{1} \mathrm{H}$ NMR spectrum as belonging to a complex of PTOBEE (Table 1). The ratio of the formed complex vs free polymer at a given concentration was calculated as the integral of signals $\mathrm{H}^{\prime \prime}+\mathrm{H} 12^{\prime \prime}$ of the complex divided by the integral of the analogous signals in the free polymer, i.e., $\mathrm{H} 8+\mathrm{H} 8^{\prime}+$ $\mathrm{H} 12+\mathrm{H}_{12}$, and these results were plotted in Figure 4.

1D-selective-TOCSY ${ }^{21,22}$ experiments were acquired for PTOBEE at $7.5 \mathrm{mg} / \mathrm{mL}$. Two experiments were acquired, where in each, the signal $\mathrm{Hc}$ of one enantiomer (Table 1) is selectively excited by a excitation-sculpting technique ${ }^{23}$ using a selective Gaussian shaped $180^{\circ}$ soft pulse of 50 ms. An MLEV-17 spin lock scheme was used during a mixing time of $100 \mathrm{~ms}$ to generate TOCSY peaks.

1D-selective-T-ROESY 21,22 experiments were acquired for PTOBEE at $7.5 \mathrm{mg} / \mathrm{mL}$. A signal corresponding to a proton $(\mathrm{Ha}, \mathrm{Hb}, \mathrm{Hc}, \mathrm{Hd}$, or $\mathrm{He}$ ) is selectively excited in each experiment by a excitation-sculpting technique ${ }^{23}$ using a selective Gaussian shaped $180^{\circ}$ soft pulse of 50 ms. The T-ROESY spinlocking mixing time was 250 ms.

A DQF-COSY experiment ${ }^{24}$ was acquired for PTOBEE at $7.5 \mathrm{mg} / \mathrm{mL}$. The accurate determination of the homonuclear vicinal couplings constants ${ }^{3} \mathrm{Ha}-\mathrm{Hc}$ and ${ }^{3} \mathrm{~J} \mathrm{Hb}-\mathrm{Hc}$ in the polymer was acomplished by a deconvolution of the COSY cross-peaks multiplets using the program DECO within the XWIN-NMR spectrometer software.

2D-DBP-LED DOSY experiments ${ }^{25,26}$ were performed for PTOBEE $67 \%$ ee at the following concentrations: $7.5,3.75$, $1.87,0.94,0.47,0.23,0.12$, and $0.06 \mathrm{mg} / \mathrm{mL}$. Another DOSY experiment was acquired for the sample $7.5 \mathrm{mg} / \mathrm{mL}$ of PTO-

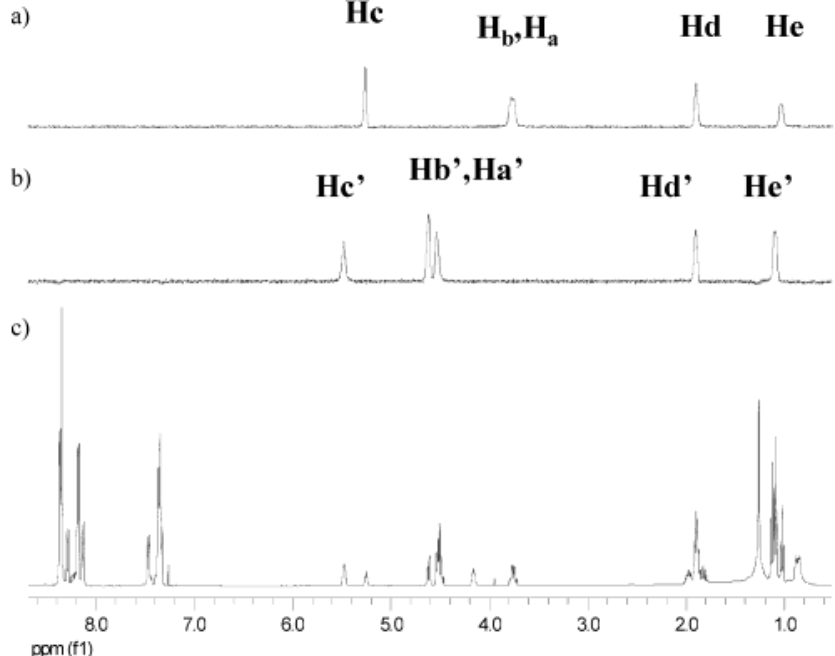

Figure 2. 1D-selective TOCSY experiments of PTOBEE: (a) signal $\mathrm{Hc}$ was selectively excited; (b) signal $\mathrm{HC}^{\prime}$ was selectively excited; (c) ${ }^{1} \mathrm{H}$ NMR (7.5 mg/mL).

BEE $58 \%$ ee. To minimize errors in the diffusion constants the sample volume was set to a minimum to avoid flow currents and a purge gradient was applied during the longitudinal magnetization storage periods. ${ }^{27-30}$ The diffusion delay was set to $400 \mathrm{~ms}$ and gradients applied were sine shaped and had a duration of $1 \mathrm{~ms}$ with $200 \mu \mathrm{s}$ of recovery delay. The gradient amplitude was linearly increased from 2 up to $50 \mathrm{G}$ $\mathrm{cm}^{-1}$ in 64 different blocks of the experiment. The diffusion value was estimated by a fit of the intensity to the corresponding DOSY gradient strength, which are related by the wellknown Stejskal-Tanner equation. ${ }^{25,26}$ These fits were done with the MestRe-C processing program. ${ }^{20}$

Cross-saturation transferred difference (cross-STD) experiments ${ }^{17-19}$ were acquired for the $0.12 \mathrm{mg} / \mathrm{mL}$ sample of the PTOBEE $67 \%$ ee. The two separated aromatic signals assigned to a complex of PTOBEE, H12" + $\mathrm{H}^{\prime \prime}$ and H7" in Table 1 , were chosen for two independent saturation experiments. In each of these cross-STD experiments the signal selected is saturated by application of a low power proton pulse at a frequency which is alternatively changed during the saturation period to cover the complete line width of the signal. A crossSTD experiment of reference was acquired under similar conditions except that the saturation frequency was set in a region of the spectrum which does not affect any resonance. Cross-STD were acquired with 1024 scans and $2 \mathrm{~s}$ of interscan delay period. The experiments were repeated using saturation times of 1,3 , and 5 s to check the consistency of the observed enhancements.

Circular Dichroism (CD). CD absortion spectra were measured for samples of polymer PTOBEE with $67 \%$ and $58 \%$ ee at concentrations 20 and $0.07 \mathrm{mg} / \mathrm{mL}$ in $\mathrm{CDCl}_{3}$. The spectra were acquired in a spectropolarimeter J asco J -720 operating in a range of wavelengths between 210 and $400 \mathrm{~nm}$. 
a)
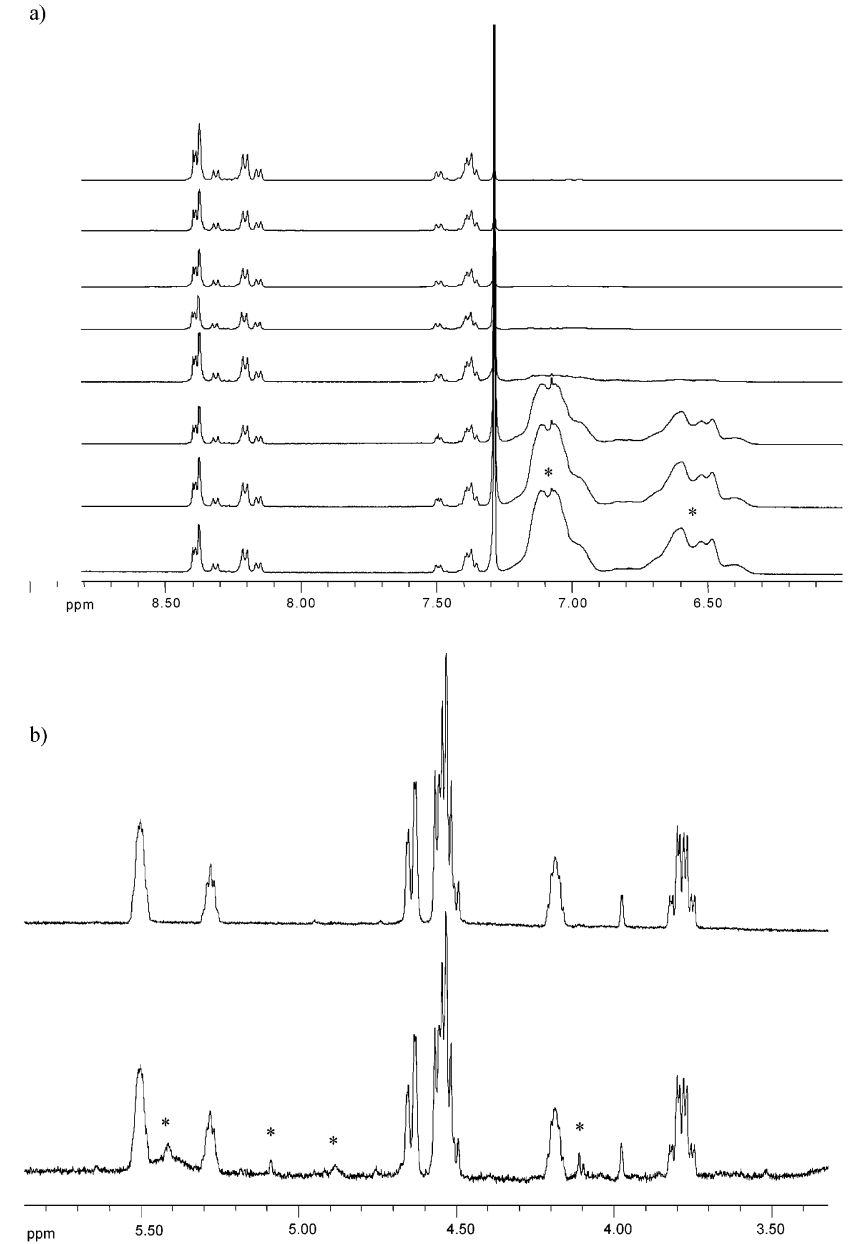

Figure 3. Dilution ${ }^{1} \mathrm{H}$ NMR experiments of PTOBEE $(67 \%$ ee) in $\mathrm{CDCl}_{3}$. (a) Aromatic region: concentrations from top to bottom are 7.5, 3.75, 1.87, 0.94, 0.47, 0.23, 0.12, and $0.06 \mathrm{mg} /$ $\mathrm{mL}$. (b) Aliphatic region: concentration from top to bottom 7.5 and $0.06 \mathrm{mg} / \mathrm{mL}$. Signals correponding to the complex are indicated with asterisks.

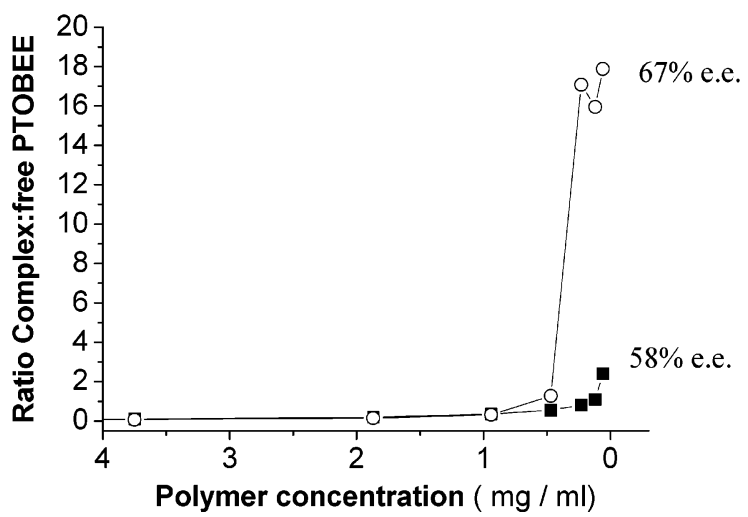

Figure 4. Plot of the calculated ratio complex:free polymer for samples: PTOBEE $67 \%$ (open circles) and $58 \%$ ee (filled squared) in $\mathrm{CDCl}_{3}$. The plot was obtained by integration of the ${ }^{1} \mathrm{H}$ NMR signals at different concentrations (see experimental part).

Mass Spectrometry (MS). A MS spectra was acquired in a Bruker-Autoflex MALDI-TOF mass spectrometer for a sample of PTOBEE $67 \%$ ee diluted in THF and placed in a dithranol matrix.

\section{Results}

Cholesteric PTOBEE (Figure 1) had been previously characterized by simultaneous WAXS/SAXS with syn- chroton radiation source, measurements of thermal stability (DSC), optical rotatory dispersion (ORD), circular dichroism (CD) and ${ }^{1} \mathrm{H}$ and ${ }^{13} \mathrm{C}$ NMR and molecular modeling. $6,7,10$

The complete assignment of the ${ }^{1} \mathrm{H}$ and ${ }^{13} \mathrm{C}$ chemical shifts of PTOBEE was accomplished by a combination of HMQC, HMBC, DQF-COSY, and TOCSY experiments (data not shown). These results are given in Table 1 and complement those reported in a previous study of this polymer. ${ }^{6} \mathrm{~A}$ different set of ${ }^{1 \mathrm{H}}$ and ${ }^{13} \mathrm{C}$ NMR signals was obtained for each of the two possible enantiomeric repeating units incorporated in the polymer (Figure 1), since they form diasteroisomers when they are incorporated in the same polymer chain, introducing differences in their microstructural environment. An analogous chemical shift distinction of otherwise chemically equivalent nuclei has been reported in polymers with stereoirregular structures. ${ }^{31}$ The set of aliphatic signals of PTOBEE corresponding to each enantiomer can be easily identified in the 1D-selective TOCSY experiment, the transference from the well isolated proton $\mathrm{Hc}$ identifies the rest of the protons $\mathrm{Ha}$, $\mathrm{Hb}, \mathrm{Hd}$, and $\mathrm{He}$ in each enantiomer (Figure 2). A different test of the enantiomeric distinction by NMR was provided by the ${ }^{13} \mathrm{C} C \mathrm{CP} / \mathrm{MAS}$ spectrum of the solid polymer (data not shown). This experiment showed an independent set of signals for each enantiomer discarding the possibility that they were the product of any undergoing conformational exchange equilibrium in solution.

The enantiomeric excess of the sample was determined by integration of the corresponding set of aliphatic protons $\mathrm{Ha}, \mathrm{Hb}$, and $\mathrm{Hc}$ in the ${ }^{1} \mathrm{H}$ NMR spectrum of each enantiomer that are conveniently well separated, and the value obtained for two samples of PTOBEE prepared was $67 \%$ and $58 \%$ ee.

NMR Dilution and Diffusion Studies. Dilution ${ }^{1} \mathrm{H}$ NMR experiments of the sample with $67 \%$ ee in $\mathrm{CDCl}_{3}$ showed the gradual appearance of several new broad signals in the spectrum which coexist with the signals previously identified as the free polymer (Figure 3 ). These changes were fully reversible and the broad signals appearing at the lower concentrations were identified as the product of a self-association process between the PTOBEE polymer chains to give a complex. There is a clear tendency of the complex to be formed in diluted samples (Figure 3), in fact in the range of concentrations explored, the formation of the complex prevails over the polymer free chains for concentrations bell ow $0.47 \mathrm{mg} / \mathrm{mL}$, while at higher polymer concentrations, the free polymer species are predominant (F igure 4).

A different test of this self-aggregation tendency in samples of PTOBEE $67 \%$ and $58 \%$ ee was provided by CD. A strong phase transition from 290 to $310 \mathrm{~nm}$ appears when going from a concentration of $20 \mathrm{mg} / \mathrm{mL}$ to one of $0.07 \mathrm{mg} / \mathrm{mL}$, an effect attached to the formation of the complex (Figure S1).

Further information about the species present in solution at $0.06 \mathrm{mg} / \mathrm{mL}$ was obtained by DOSY diffusion NMR experiments. The diffusion curves of Figure 5, parts a and b, clearly show that all the aliphatic and aromatic signals of both enantiomers in the free (or nonaggregated) polymer decay in a very similar way; i.e., they experience the same diffusion. This result is consistent with our previous interpretation during the signal assignment that both enantiomers are forming 
a)

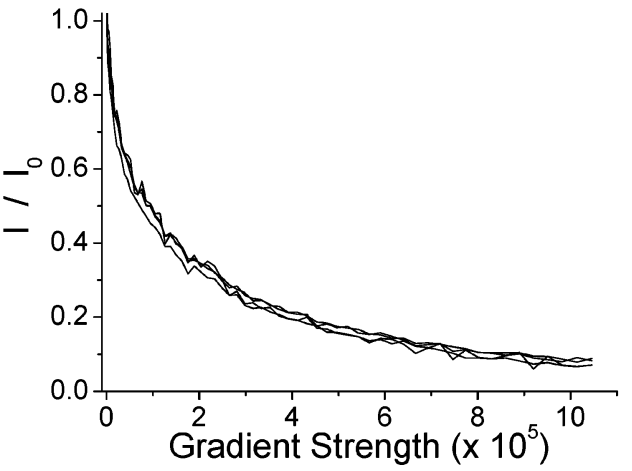

b)

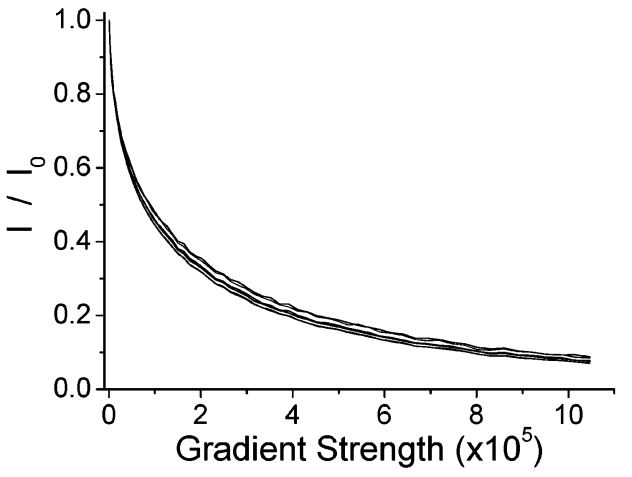

c)

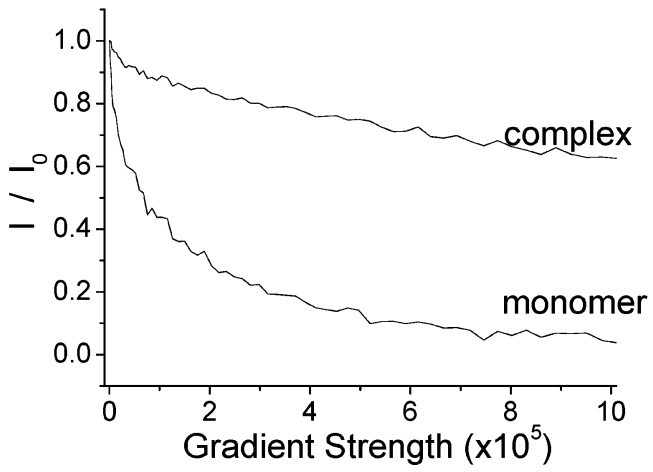

Figure 5. Plots of the DOSY diffusion decay of different signals of PTOBEE $67 \%$ (concentrated $0.06 \mathrm{mg} / \mathrm{mL}$ ). The experimental normalized intensity is plotted vs the strength of the diffusion encoding gradient, every two adjacent points are connected by a straight line. (a) Four curves of the aliphatic signals $\mathrm{Ha}, \mathrm{Hb}+\mathrm{Hc}, \mathrm{Ha}^{\prime}, \mathrm{Hb}^{\prime}+\mathrm{HC}^{\prime}$. (b) Six curves of the aromatic signals $\mathrm{H} 12, \mathrm{H} 7, \mathrm{H} 8, \mathrm{H}^{\prime} 2^{\prime}, \mathrm{H}^{\prime}, \mathrm{H}^{\prime}$. c) Curves of an aromatic signal in the complex $\left(\mathrm{H}^{\prime \prime} 2^{\prime \prime}+\mathrm{H}^{\prime \prime}\right)$ and in the free polymer $\left(\mathrm{H}_{12}\right)$.

part of the same polymer molecule. On the other hand, remarkable differences are seen when comparing the diffusion curve of a signal of the complex with other of the free polymer (Figure 5c). A fit of the DOSY curve to the Stejskal-Tanner equation 25,26 gives values of 4.45 $\pm 0.12 \mathrm{e}^{-7}$ and $3.94 \pm 0.20 \mathrm{e}^{-6} \mathrm{~cm}^{2} \mathrm{~s}^{-1}$ for the complex and the free polymer species, respectively, which is consistent with the larger size of the former.

The MS spectrum of PTOBEE $67 \%$ allowed us to determine the exact molecular weight of the free monomer polymer. The molecular ion peak observed at maximum m/z was 2838.26, a value which corresponds to six repeating units of PTOBEE. From this peak either three consecutive fragmentation steps, each one with a loss of mass of 460 corresponding to a repeating unit in the polymer and/or a distribution of polymer chains with a smaller degree of polymerization (from 5 to 3 ) could generate the other peaks observed at $\mathrm{m} / \mathrm{z} 2379.0$,
1919.14, and 1459.28. The loss of a repeating unit of PTOBEE without the terminal fragment $\mathrm{O}-\mathrm{CH}\left(\mathrm{CH}_{2}-\right.$ $\left.\mathrm{CH}_{3}\right)-\mathrm{CH}_{2}$ (Figure 1 ) gives a loss of mass of 388 units (i.e., 460-72) that could correspond to the fragmentation of the four previous peaks mentioned to give the following observed peaks at $\mathrm{m} / \mathrm{z}$ 2451.27, 1991.27, 1531.35 and 1074.85.

The results provided by MS gives a maximum degree of polymerization of 6 and the possibility that chains with smaller degree of polymerization from 5 to 3 also be present in solution. In such case, the diffusion value determined by NMR for the free polymer monomer would correspond to a weighted average of the different species collapsing at a given chemical shift. 32 The relative fast diffusion value obtained by NMR for the free uncomplexed polymer would be consistent with this explanation.

Self-Aggregation Equilibrium. The chemical shift differences between comparable signals of the free monomer and its complex of Table 1 and the dependence of the intensities with the concentration of the polymer were indicative of a slow exchange equilibrium between them. The possibility that other possible self-associated species (dimers, trimers, etc.) could be in fast exchange and resonate within the signals of the free polymer was tested by additional DOSY diffusion measurements of PTOBEE $67 \%$ ee at concentrations ranging from 7.5 to $0.06 \mathrm{mg} / \mathrm{mL}$. After correction for the viscosity, the small differences in the NMR diffusion values obtained refuted this possibility, since a fast exchange equilibrium would have resulted in a significant and systematic change in diffusion with concentration because of the averaging between the free polymer and complex species. ${ }^{32}$

Cross-saturation difference experiments (cross-STD) ${ }^{17,18}$ provided further insight of the undergoing slow exchange equilibrium between the free polymer and its complex. In a cross-STD experiment the transference of saturation from the irradiated signal may produce an enhancement or diminution in the intensity of other signals within the same or in a different molecule, that is, mediated by two possible mechanisms, the dipolar interaction (NOE) and/or the intermolecular exchange. The irradiation of the broad signal $\mathrm{H}^{\prime \prime}+\mathrm{H} 12^{\prime \prime}$ of the complex showed an expected strong intramolecular NOE between $\mathrm{H}^{\prime \prime}$ and $\mathrm{H}^{\prime \prime}$ (Figures 6b). Also in this spectrum, a strong intermolecular enhancement of signals $\mathrm{H}^{\prime}$ and $\mathrm{H} 8$ in the free polymer chains is observed, that must be caused by an intermol ecular exchange process with the irradiated H8". Some other smaller peaks observed in Figure $6 \mathrm{~b}$ are the protons $\mathrm{H}^{7}$ ' and $\mathrm{H} 7$, which are the result of a two-step mechanism that involves the previously seen intermolecular exchange complexfree polymer of signal $\mathrm{H}^{\prime \prime}$ with $\mathrm{H}^{\prime}$ and $\mathrm{H} 8$, followed by the intramolecular NOE from $\mathrm{H}^{\prime}$ to $\mathrm{H}^{7}$ ' and from $\mathrm{H} 8$ to $\mathrm{H} 7$ in the free polymer.

The irradiation of signal H7" in the cross-STD experiment of Figure $6 c$ resulted in an expected strong intramolecular NOE in the complex with proton H8". Other strong peaks observed in this figure are protons $\mathrm{H}^{\prime}$ and $\mathrm{H} 8$ which are the result of a two step process which implies the mentioned intramolecular NOE from $\mathrm{H}^{\prime \prime}$ to H8" followed by the intermolecular exchange complex-free polymer of $\mathrm{H}^{\prime \prime}$ " with $\mathrm{H}^{\prime}$ and $\mathrm{H} 8$.

These cross-STD results clearly evidence an undergoing slow exchange equilibrium between the complex and the free polymer molecules. 
a)

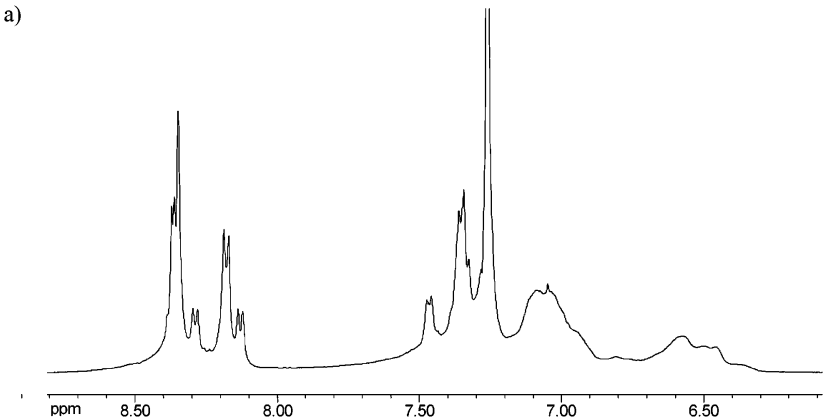

b)

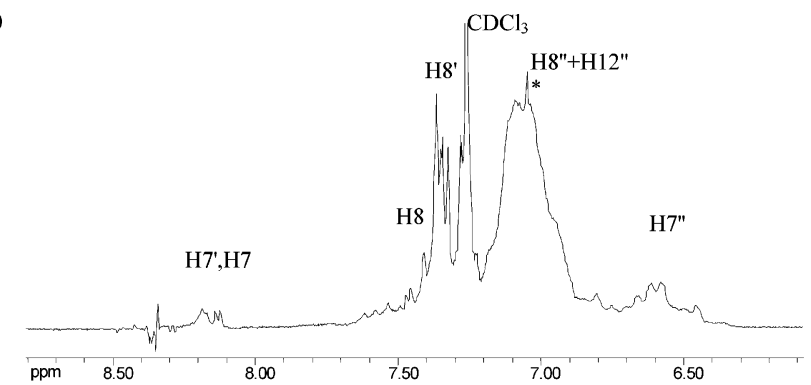

c)

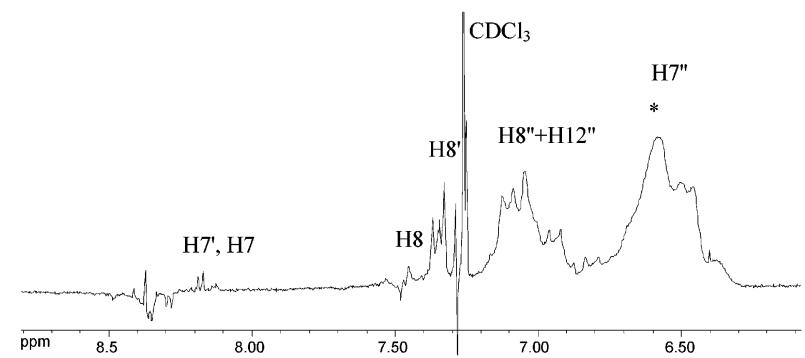

Figure 6. Cross-saturation difference spectra obtained for the polymer PTOBEE $67 \%$ ee (concentrated $0.12 \mathrm{mg} / \mathrm{mL}$ ); (a) reference saturation experiment; (b) saturation of signal s $\mathrm{H}^{\prime \prime}$ + $\mathrm{H}_{12}$; ; (c) saturation of signal $\mathrm{H}^{\prime \prime}$. The signal/s saturated in each case are indicated with an asterisk.

Conformational Exchange. Conformational exchange can be detected from the changes observed in the ${ }^{1} \mathrm{H}$ NMR experiments upon a change in the temperature. For the sample PTOBEE $67 \%$ ee (concentrated $0.06 \mathrm{mg} / \mathrm{mL}$ ), the splitting in the aromatic signal $\mathrm{H7}^{\prime}$ becomes better resolved when going from room temperature to about $-15{ }^{\circ} \mathrm{C}$ (Figure S2). This change is accompanied by a small but consistent deshielding effect of the aromatic protons $\mathrm{H}_{12}, \mathrm{H} 12$, and $\mathrm{H}^{\prime}$. These observations are indicative of a relative freezing in the conformational exchange (ring flipping) of the three aromatic rings of the free polymer at the lower temperatures, while they are in moderately fast conformational exchange at room temperature. The effects observed in other signals of the free polymer upon reduction of the temperature were simply a tendency to increase its line broadening, an expected effect due to the faster transverse $\mathrm{T}_{2}$ relaxation.

The possible conformational exchange in the complex was also investigated. In this case the effect of the temperature on the ${ }^{1} \mathrm{H}$ NMR resonances was not very informative because of the inherent broadness of these signals. The only temperature effect detected is that $\mathrm{T}_{2}$ relaxation becomes far more efficient for the $\mathrm{H} 7$ " than for the $\mathrm{H}^{\prime \prime}+\mathrm{H}^{\prime \prime} 2^{\prime \prime}$ signal upon a reduction of the temperature.

An indication of conformational exchange in the complex was obtained by a closer inspection of the cross-

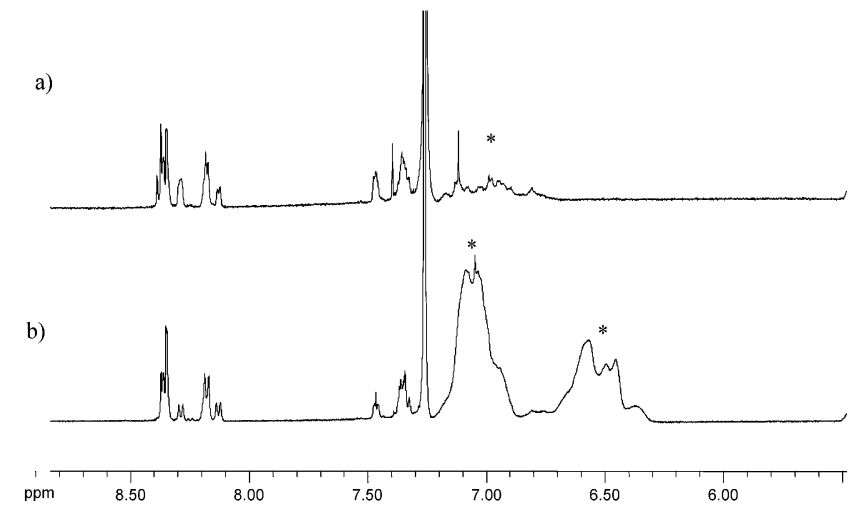

Figure 7. Comparison of the aromatic region in the ${ }^{1} \mathrm{H} N M R$ spectra in the PTOBEE polymer: (a) PTOBEE 58\% ee and (b) PTOBEE $67 \%$ ee The sample concentration in both cases is $0.06 \mathrm{mg} / \mathrm{mL}$. Signals marked with an asterisk were assigned to a complex formed by self-aggregation of the polymer.

STD experiments. Signals of protons $\mathrm{H}^{\prime \prime}$ " and $\mathrm{H}$ 7" were better resolved in these spectra than in the regular proton spectrum (Figure 6, parts $b$ and $c$ ), and they both showed a pattern that grossly resembles three separated doublet components. Such a heterogeneity in the chemical shifts would be expected when the two polymer chains are not perfectly symmetrically accommodated along the complex, or in other words, there is a relative unspecific association of the PTOBEE polymer chains in the complex. From the patterns observed in the complex it can be said that there are at least three major different arrangements of the aromatic rings in slow or no exchange at room temperature.

Comparison of Two Samples with Different Enantiomeric Excess. The determination of the amount of complex formed vs the amount of free polymer at different concentrations was done by integration of the corresponding ${ }^{1} \mathrm{H}$ NMR signals. These results shown in Figure 4 serve to compare the selfassociation tendency of two samples of PTOBEE pre pared from the same starting materials and obtained with $58 \%$ and $67 \%$ ee. The plot of Figure 4 dearly denotes a much higher disposition to aggregate for the sample obtained with $67 \%$ ee than the sample with $58 \%$ ee specially at concentrations bellow $0.47 \mathrm{mg} / \mathrm{mL}$. An illustrative picture of the higher propensity of the sample $67 \%$ ee with respect to the $58 \%$ ee sample can be seen in the signals of the complex in the ${ }^{1} \mathrm{H}$ spectra of Figure 7 obtained at the same concentration.

A final check that demonstrated that these differences in aggregation are only due to their difference in the enantiomeric excess and not by a possible different degree of polymerization in the samples was provided by DOSY NMR diffusion measurements, which gave quite similar diffusion values of the free polymer in both samples.

These results imply that the propensity for aggregation in an excess of $\mathrm{CDCl}_{3}$ solvent depends on the particular value of ee of the PTOBEE polymer, suggesting a possible explanation for the unexpected enantiomeric excess obtained during the preparation of this polymer under achiral conditions. Polymer units having a certain excess of one of the enantiomers could result in a privileged spatial geometry of the substituents which favors its self-aggregation, and possibly resulting in a more thermodynamically stable phase in an excess of organic solvent. This could be the case of polymer PTOBEE, where the first sample isolated from the 
Table 2. Experimental and Calculated ${ }^{3} \mathrm{~J}$ нн Coupling Constants (Hz) for the E nantiomer with the Greatest ee in PTOBEE (ee 67\%) and Calculated for the Conformer Obtained

\begin{tabular}{cccc}
\hline & expt $(\mathrm{Hz})$ & calcd $(\mathrm{Hz})$ & dihedral (deg) \\
\hline 3J $\mathrm{Ha}-\mathrm{Hc}$ & 11.4 & 10.5 & 171.6 \\
35 $\mathrm{Hb}-\mathrm{Hc}$ & 7.3 & 6.2 & 51.8
\end{tabular}

reaction product has a $58 \%$ ee, while after a certain time, in an excess of toluene, it precipated with $67 \%$ ee.

Conformational Study of the Polymer and Its Complex. A previous molecular modeling of the PTO$B E E$ polymer ${ }^{10}$ built models incorporating 10 repeating units of this polymer and determined several low energy conformations. These structures were tested for qualitative agreement with the available structural NMR data in solution.

The vicinal coupling constants ${ }^{3} \mathrm{Ha}-\mathrm{Hc}$ and ${ }^{3} \mathrm{H} \mathrm{Hb}-\mathrm{Hc}$ of the polymer can be related to backbone torsion angle $\phi$ of the polymer (Figure 1) by using a Karplus type equation. ${ }^{33}$ The relative large values of these two couplings ${ }^{3} \mathrm{Ha}-\mathrm{Hc} 11.4 \mathrm{~Hz}$, and ${ }^{3} \mathrm{~J} \mathrm{Hb}-\mathrm{Hc} 7.3 \mathrm{~Hz}$, indicate that the rotational motion around this torsion angle is somewhat restricted. The two prochiral protons $\mathrm{Ha}$ and $\mathrm{Hb}$ were identified in each molecular model for maximum agreement with the angles deduced from the Karplus relationship with the scalar couplings, and those low energy conformers that were not able to reproduce these couplings were rejected.

The 1D selective T-ROESY experiment offered high sensitivity (F igure S3) and provided a second structural test for the resulting models. The most structurally informative T-ROEs in PTOBEE are those between its aromatic part and its aliphatic part. From the different aromatic signals of PTOBEE, experimentally only the aromatic proton $\mathrm{H}^{\prime}$ (and possibly $\mathrm{H} 7$ ) gave $\mathrm{T}-\mathrm{ROE}$ cross-peaks with the aliphatic part, although their intensity is quite small (Figure S3).

A single PTOBEE low energy conformation was found with the best agreement with the scalar couplings and the T-ROESY data. A view of this conformer is given in Figure 8, parts $a$ and $b$, and a comparison of its geometry with the NMR results is given in Tables 2 and 3 , respectively. The conformation obtained adopts a fairly extended helical structure (helix turn of $\sim 110 \AA$ ) as a result of the linearity imposed by a repeating unit with three consecutive aromatic rings. This single static conformer may represent many of the main features of the free polymer chain, however other effects such as the aromatic ring flipping detected in the variable temperature experiments (Figure S2) may require considering a dynamic model based on several structures for which we do not have enough experimental data to define.

With respect to the structure of the complex, the NMR data are still more scarce, although some important a)
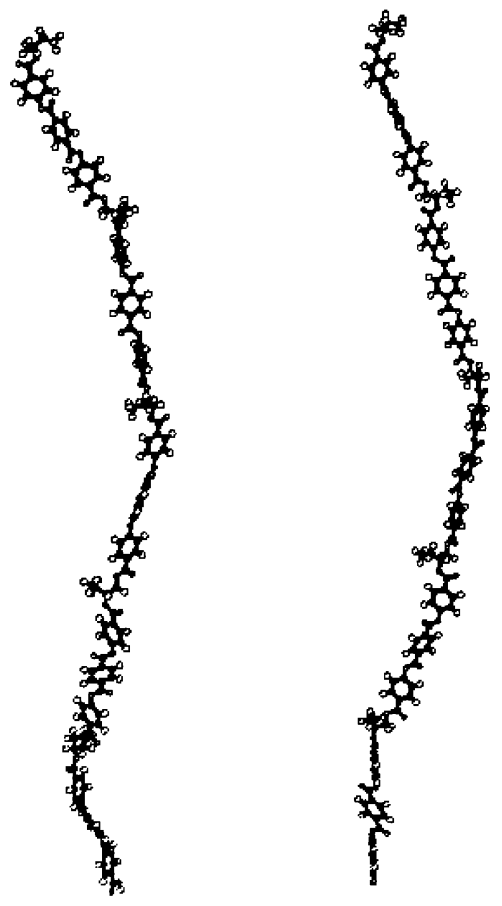

b)

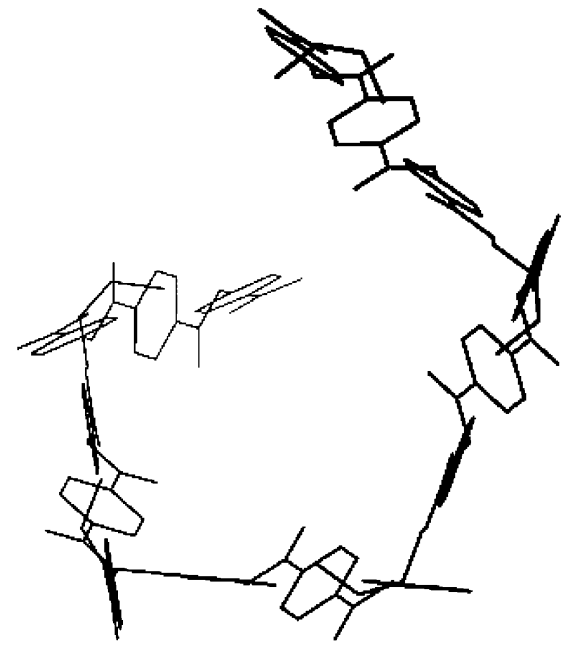

Figure 8. View of the conformation of PTOBEE found in best agreement with the NMR structural data: (a) stereoview of the lateral view; (b) top view.

facts can still be deduced. The significant shielding in the aromatic proton and carbon resonances with respect to the free polymer (Table 1) can only be explained by a ring current shift effect that requires a relative closeness and parallel alignment of the aromatic rings of two polymer units in the complex. The favorable stacking interactions established by this arrangement could

Table 3. Experimental 1D-selective-ROESY Intensities (\%) for the Enantiomer with the Greatest ee in PTOBEE Sample (ee 67\%) and Distances in the Conformer Obtained in Best Agreement

\begin{tabular}{|c|c|c|c|c|c|c|c|c|c|c|}
\hline & \multicolumn{2}{|c|}{$\mathrm{Ha}$} & \multicolumn{2}{|c|}{$\mathrm{Hb}$} & \multicolumn{2}{|c|}{$\mathrm{Hc}$} & \multicolumn{2}{|c|}{$\mathrm{Hd}$} & \multicolumn{2}{|c|}{$\mathrm{He}$} \\
\hline & expt (\%) & dist $(\AA)$ & expt (\%) & dist $(\AA)$ & expt (\%) & $\operatorname{dist}(\AA)$ & expt (\%) & dist $(\AA)$ & expt (\%) & $\operatorname{dist}(\AA)$ \\
\hline $\mathrm{Ha}$ & & & 30.2 & 1.80 & 2.1 & 3.10 & 0.2 & $3.27^{a}$ & 0.2 & $3.4^{b}$ \\
\hline $\mathrm{Hb}$ & 25.1 & 1.80 & & & 2.9 & 2.46 & 0.6 & $3.73^{a}$ & 0.0 & $4.5^{b}$ \\
\hline $\mathrm{Hc}$ & 5.5 & 3.10 & 7.7 & 2.46 & & & 1.3 & $2.42^{\mathrm{a}}$ & 0.0 & $3.8^{b}$ \\
\hline $\mathrm{Hd}$ & 2.9 & $3.27^{a}$ & 2.9 & $3.73^{a}$ & 4.6 & $2.42^{\mathrm{a}}$ & & & 1.5 & $2.7^{\mathrm{b}}$ \\
\hline $\mathrm{He}$ & 1.5 & $2.37^{a}$ & 0.0 & $3.91^{a}$ & 2.4 & $3.79^{a}$ & 3.2 & $3.34^{a}$ & & \\
\hline $\mathrm{H} 7$ & 0.9 & $4.60^{\mathrm{a}}$ & 0.6 & $4.56^{a}$ & 1.0 & $4.55^{a}$ & 0.4 & $3.69^{a}$ & 0.1 & $4.0^{b}$ \\
\hline
\end{tabular}

a Proton with the closest distance in the model. ${ }^{\mathrm{b}}$ Average distance 
provide an important source of enthalpic stability to the complex.

A NOESY experiment obtained for PTOBEE $67 \%$ ee (concentrated $0.06 \mathrm{mg} / \mathrm{mL}$ ) (data not shown) showed very intense cross-peaks between proton $\mathrm{H}^{7}$ " of the complex with the aliphatic protons $\mathrm{Hd}^{\prime}, \mathrm{He}^{\prime}, \mathrm{Hd}$, and He. Comparing the strong intensity of the mentioned NOEs observed with the same very weak T-ROESY cross-peaks obtained in the nonaggregated polymer (Figure S3), these NOEs should correspond to interstrand NOEs, under the assumption that a similar extended structure is maintained in the complex. At this point we do not have sufficient experimental information to built a more detailed structure of the complex, a model based in multiple conformations should be required in accordance with the conformational exchange results.

\section{Summary and Conclusions}

The synthesis of the cholesteric, chiral polymer PTO$B E E$ from racemic materials showed the unexpected stereosel ective separation of polymer units of PTOBEE which incorporate a higher excess of one enantiomer at the expense of the other when the polycondensation reaction products are decanted into a large excess of toluene.

The NMR study of the cholesteric PTOBEE revealed the propensity of samples obtained with a certain enantiomeric excess to form a complex in solution by a self-association process. The formation of the complex is favored in the samples by further dilution in chloroform to concentrations bel ow $0.47 \mathrm{mg} / \mathrm{mL}$. The effect of the particular value of the enantiomeric excess of the sample has an enormous impact in its tendency to aggregate.

These results suggest that both effects, the enantiomeric excess obtained during the synthetic process and the high propensity to the formation of the complex in diluted samples of this polymer could be related. Polymer units incorporating a certain excess of one of the enantiomers could result in a privileged spatial geometry of the substituents which favors its self-aggregation, resulting in its precipitation during the synthetic process at two different kinetic rates.

The structural study of the nonaggregated polymer showed that it adopts a highly linearly extended helical conformation. In the case of the complex, a relative closeness and parallel alignment of the aromatic rings of two different polymer units can be inferred from the data, consistent with favorable aromatic stacking interactions as a driving force for the formation of this complex.

\section{Abbreviations \\ DOSY diffusion ordered spectroscopy \\ ee enantiomeric excess \\ NOE nuclear Overhauser effect \\ T-ROESY transverse rotating frame Overhauser effect \\ PFG-STE pulse field gradient-stimulated echo \\ DBP-LED double bipolar gradient-longitudinal eddy current delay \\ cross-STD cross-saturation transfer difference}

Acknowledgment. The authors would like to thank Prof. J esús J iménez-Barbero for hel pful discussions and Dr. J uan Carlos Cobas by his support with the MestRe-C processing program. We also thank the CSIC for the financial support of R.M.B.

Supporting Information Available: Figure S1, CD spectra of PTOBE E, Figure S2, ${ }^{1} \mathrm{H}$ NMR spectra of PTOBEE, and Figure S3, 1D selective T-ROE SY experiments obtained for different selected signals of PTOBEE polymer. This material is available free of charge via the Internet at http:// pubs.acs.org.

\section{References and Notes}

(1) McEIheny, D.; Frydman, V.; Zhou, M.; Frydman, L. J . Phys. Chem. B 1999, 103, 9505-9511.

(2) Liquid Crystalline Polymer Systems; Isayev, A. I., Kyu, T., Cheng, S. Z. D., Eds.; American Chemical Society: Washington, DC, 1996.

(3) Polson, J . M.; Zuckermann, M. J . J . Chem. Phys. 2002, 116, 7244-7254.

(4) Peng, B.; J ohannsmann, D.; J ürgen, R. Macromol ecules 1999, $32,6759-6766$

(5) Skorokhodov, S. S.; Bilibin, A. Y. Makromol. Chem. Makromol. Symp. 1989, 29, 9.

(6) Pérez-Méndez, M.; Marco, C. Acta Polym. 1997, 48, 502-506.

(7) Advances in Biochirality; Palyi, G., Zucchi, C., Caglioti, L. Eds.; Elsevier Science, S. A.: 1999; Chapter 24, pp 325-334.

(8) Pérez-Méndez, M.; Marco, C.; Marco, R. Patent number ES2125818 A, 1999-03-01.

(9) Pérez-Méndez, M.; Rocha, M. US Patent number 6,165,382, December 2000

(10) Fayos, J .; Sánchez-Cortés, S.; Marco., C.; Pérez-Méndez, M. J Macromol. Sci.-Phys. B 2001, 40, 553-576.

(11) Holstein, P.; Bender, M.; Galvosas, P.; Geschke, D.; Kärger J.J. Magn. Reson. 2000, 143, 427-430.

(12) J ayawickrama, D. A.; Larive, C. K.; McCord, E. F.; Roe, D. C. Magn. Reson. Chem. 1998, 36, 755-760.

(13) Mayer, C.; Hoffmanm, D.; Wohlgemuth, M. Int. J . Pharm. 2002, 242, 37-46.

(14) Yao, S.; Howlett, G. J .; Norton, R. S. J . Biomol. NMR 2000, 16, 109-119.

(15) Cabrita. E. J .; Berger, S. Magn. Reson. Chem. 2002, 40, S122-S127.

(16) Dingley, A. J .; Mackay, J . P.; Chapman, B. E.; Morris, M. B.; Kuchel, P. W.; Hambly, B. D.; King, G. F. J . Biomol. NMR 1995, 6, 321-328.

(17) Mayer, M.; Meyer, B. Angew. Chem. Chem. Int. 1999, 38 , $1784-1788$

(18) Mayer, M.; Meyer, B. J . Am. Chem. Soc. 2001, 123, 61086117.

(19) Lane, A. N.; Kelly, G.; Ramosa, A.; Frenkielb, T. A. J . Biomol NMR 2001, 21, 127-139.

(20) Cobas, J . C.; Sardina, F. J . Concepts Magn. Reson. 2003, in press.

(21) Stonehouse, J .; Adell, P.; Keeler, J .; Shaka, A. J . J . Am. Chem. Soc. 1994, 116, 6037.

(22) Stott, K.; Stonehouse, J .; Keeler, J .; H wang, T. L.; Shaka, A J .J . Am. Chem. Soc. 1995, 117, 4199-4200.

(23) Hwang, T.-L.; Shaka, A. J . J . Magn. Reson. 1995, A112, 275279.

(24) Shaka, A. J .; Freeman, R. J . Magn. Reson. 1983, 51, 169.

(25) Wu, D.; Chen., A.; J ohnson, C. S., J r. J . Magn. Reson. Ser. A 1995, 117, 260-264.

(26) Wu, D.; Chen., A.; J ohnson, C. S., J r. J . Magn. Reson. Ser. A 1995, 117, 7566-7567.

(27) Gibbs, S. J .; J ohnson, C. S., J r. J . Magn. Reson. 1991, 93, 395-402.

(28) Pelta, M. D.; Barjat, H.; Morris, G. A.; Davis, A. L.; Hammond, S. J . Magn. Reson. Chem. 1998, 36, 706-714.

(29) Chen, A.; J ohnson, C. S., J r.; Lin, M.; Shapiro, M. J . J . Am Chem. Soc. 1998, 120, 9094-9095.

(30) Zhang, X.; Cong-Gang, L.; Chao-Hui, Y.; Mai-Li, L. Anal. Chem. 2001, 73, 3528-3534.

(31) Darlene, M. W.; I vey, T.; Tonelli, A. E. Macromol ecules 2002 35, 1976-1979.

(32) Cameron, K. S.; Fielding, L. Magn. Reson. Chem. 2002, 40, 106-109.

(33) Haasnoot, C. A. G.; Deleuw, F. A. A. M.; Altona, C. Tetrahedron 1980, 36, 2783-2792.

MA034982E 